Article

\title{
Integrating Ecosystem and Urban Services in Policy-Making at the Local Scale: The SOFA Framework
}

\author{
Sara Antognelli ${ }^{1}$, Marco Vizzari ${ }^{1, *(10)}$ and Catharina J. E. Schulp ${ }^{2}$ \\ 1 Department of Agricultural, Food, and Environmental Sciences, University of Perugia, 06121 Perugia, Italy; \\ antognellisara@gmail.com \\ 2 Environmental Geography Group, Institute for Environmental Studies, Vrije Universiteit Amsterdam, \\ De Boelelaan 1087, 1081 HV Amsterdam, The Netherlands; nynke.schulp@vu.nl \\ * Correspondence: marco.vizzari@unipg.it; Tel.: +39-075-585-6059
}

Received: 15 March 2018; Accepted: 28 March 2018; Published: 29 March 2018

check for updates

\begin{abstract}
Despite ecosystem services having been broadly studied in the scientific literature, they are still hardly integrated in policy-making and landscape management. The lack of operative tools for their application is a main limiting factor of such operationalization. In this work, a framework including 53 livability services produced by the biophysical and socioeconomic subsystem, or by their interaction, was developed considering a local study area. All the services were characterized in terms of the need to access their Service Benefiting Areas (SBAs, the geographical units where the services benefit consumers) from the Use Regions (URs, the usual location of users). Moreover, the Service-Providing Areas (SPAs, the geographical unit where the service is produced) were also classified and characterized. Such analysis, together with empirical observations, helped to classify the spatial relationships between the SPAs, SBAs and URs of each service. In addition to a list of detailed information about all the services included in the framework, a visual scheme representing the different SBA types and an operational flow diagram synthesizing the spatial organization of service flow were designed to apply the methodology in other study areas. Two examples show the practical applicability in policy-making of the whole framework for supporting different aspects of local decision-making.
\end{abstract}

Keywords: ecosystem and urban services; ecosystem service flow; livability; landscape services; policy-making; decision support

\section{Introduction}

\subsection{General Background}

Ecosystem Services (ESs) benefit people by meeting different human needs [1] that can include basic subsistence needs, such as water and food, needs at a higher level, like safety and belonging needs [2], and the highest-level needs related to culture, values and beliefs, such as recreation preferences [3,4]. Although Landers [5] stated that "ESs are components of the natural environment", many ESs need human input for their delivery. The degree of human input in the provision of such services varies depending on the service considered. For example, agricultural products are produced by strongly-managed ecosystems [6], while educational services can be provided by ecosystems themselves or by human activities. Many human needs, such as energy supply, transport, healthcare, food and water servicing, undeniably are typically satisfied by Urban Services (USs [7]) without strictly relying on natural systems (e.g., by providing cinemas, theatres, hospitals, public security). 
Until recently, ESs have rarely been considered as related to USs. Holistic consideration of all factors that influence human well-being is hampered due to three main reasons. First is the strong segregation between urban planning and rural planning studies. Studies about the operational use in policy-making of indicators considering the spatial relations between landscape features and ES provisions and beneficiaries are very recent (see, e.g., [8]), although such information appears essential for service delivery and trade-off management. Contrarily, there is a strong awareness that accessibility to services and amenities provided in urban areas, currently managed at the landscape level, increases people's well-being [9], and as a consequence, the management of these services is a prior concern for planners and citizens $[10,11]$.

A second barrier to holistic planning to support human well-being is found in the scale mismatch between ES processes and spatial planning [12]. ESs can function at different scales, ranging between global for carbon sequestration to local for erosion prevention [13]. At the same time, policy-makers make decisions about administrative areas that represent the scale at which landscape planners are acting. ES spatial accounting tools should support policy-makers in making these sorts of decisions, but existing spatial ES indicators often do not match policy-makers' needs. This is largely due to a lack of indicators that precisely quantify Service-Providing Areas (SPAs) (where the service are generated), as current indicators tend to concentrate the different geographical units of a service into a single component $[3,14]$. Moreover, also, SPA connections with Service Benefiting Areas (SBAs) (where the services benefit people) are hardly identifiable [8]. This makes it impossible to map, quantify or define which part of the ES supply is in the responsibility of the local planners, which part is out of their control and how they can interact with the management of the two parts.

A third barrier is that not every service benefits every citizen. For example, pollination can be considered a service for farmers, while concurring with the production of fresh fruit and vegetables. In this case, farmers benefit from pollination and fresh fruit, but other citizens only benefit from fresh fruit. Subdividing services into intermediate and final services $[5,15]$ improves the insight into which services contribute to overall livability $[11,16,17]$, but further obscures spatial relationships between place livability and ecosystems that support it.

In this study, we aim to contribute to overcoming the described barriers, providing an operational framework (called SOFA (Services Operational FrAmework)) supporting decision-making about urban and ecosystem services at the local scale. To specifically address the aforementioned issues, the framework aims to: (1) identify a significant set of priority ecosystem and urban services; (2) conceptualize and operationalize the spatial linkages between service-providing areas and service beneficiaries; and (3) design a scheme supporting the selection of the scale of required action and the most appropriate actors. Finally, the framework aims at offering guidance for supporting management actions at the local scale by synthesizing the different concepts and tools into usable schemes.

\subsection{Key Concepts}

The approach used for SOFA development is based on two key background concepts: (1) the conceptual links between ESs and USs; (2) the scale (mis)matches between supply-demand areas and the planning regions.

\subsubsection{Linking ESs and USs}

Place livability is a concept that can guide the identification of services supporting the livability of a landscape by its inhabitants, and with that, the context dependency of human needs. Place livability can be defined as the attractiveness and suitability of a place [16] and is a strictly anthropocentric concept [11,17]. Livability is becoming a main focus of many recent public policies (see, e.g., [18-21]), is inherently dependent on ESs and USs [17] and often applies at the local scale, at which individuals interact with their environment. ESs can be considered as the structural and functional ecosystem contributions to human well-being that often occur in combination with anthropogenic inputs [22-25]. The degree of human input in the provision of such services varies depending on the services. For example, agricultural products are produced by strongly-managed 
ecosystems [6], while educational services can be provided by ecosystems themselves or by human activities. Other human needs, such as energy supply, transport, healthcare, food and water servicing, undeniably are satisfied without strictly relying on natural systems (e.g., by providing cinemas, theatres, hospitals). These services are completely produced by the socioeconomic subsystem [26,27] and are usually called urban amenities [28] or Urban Services (USs) [7]. USs increase urban attractiveness and are usually managed by landscape planners at the municipal or supra-municipal level. In this view, a sliding scale between the contribution of the socioeconomic subsystem and the biophysical subsystem can be recognized in the production of the different types of services (Figure 1).

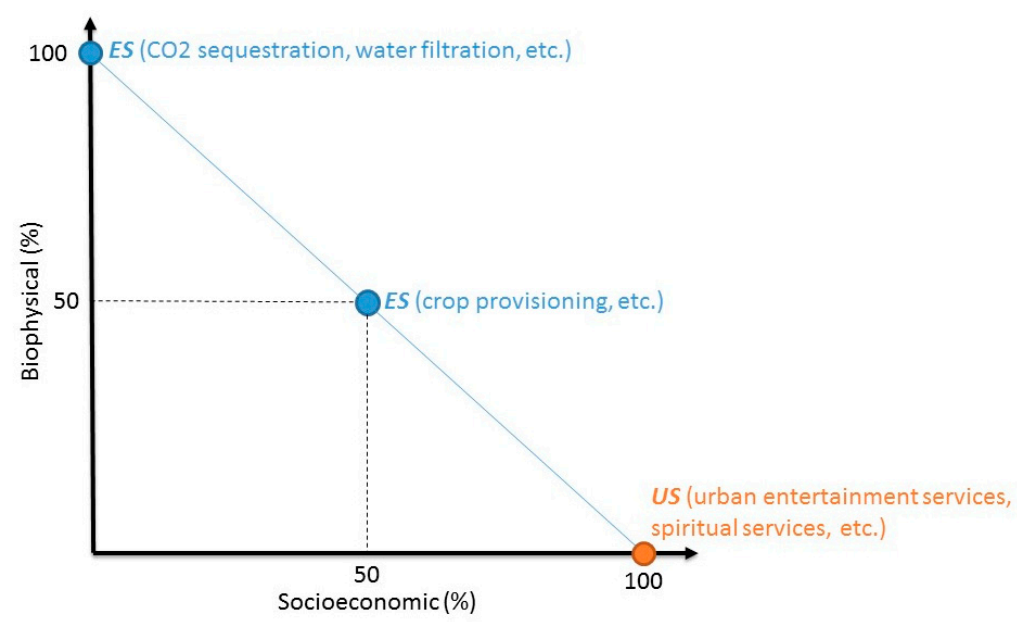

Figure 1. Differences between Ecosystem Services (ESs) and Urban Services (USs) based on the composition of service-providing areas.

\subsubsection{Scale (Mis)Matches: Supply-Demand Areas and the Planning Regions}

The ES flow defines the spatial connection between the SPAs, the SBAs and Use Regions (URs) intended as "the location of users-usually human beneficiary groups—on the landscape" [29]. The literature about mapping of ESs (see, e.g., [30-33]) suggested that an effective operationalization of ES flows is difficult to achieve. This is because commonly, no distinction is made between the flow of the service and the action required by the beneficiary to benefit from the service. Nevertheless, such differentiation is useful for operational purposes since it supports a better identification of where management is needed to ensure service delivery. In this regard, spatial relationships between SPAs and SBAs were investigated by Fisher [34] who distinguished between "in situ" (when SPA and SBA overlap), "omni-directional" (when SBA extends SPA without any directional bias), "directional, slope dependent" (when SBA lies downslope (downstream) from SPA) and "directional, slope independent" (when SBA lies only on one side of the SPA). In the three latter cases, Service Connecting Areas (SCAs) connect SPAs to SBAs (Figure 2). To identify the connection between URs and SBAs, we propose the concept of Service Access Areas (SAAs). However, people living in the UR can access the SPAs [35] by the SAAs (Figure 2), but the need to access the services may not occur in some cases [17], as URs may overlap with SBAs.

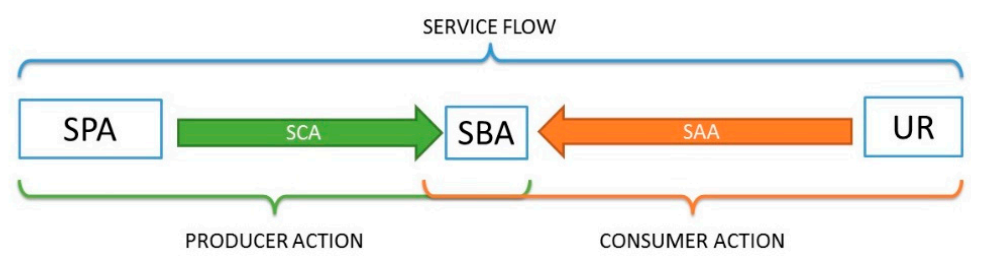

Figure 2. Conceptual framework of the service flows. SPA: Service-Providing Area; SCA: Service Connecting Area; SBA: Service Benefiting Area; SAA: Service Access Area; UR: Use Regions. 
The identification of the spatial relation between SBAs and URs implies that URs (and so the service benefiters) can be spatially identified. However, the literature about ESs suggests that some services do not benefit the final users directly but are rather necessary to the production of other services. To this aim, in the ES literature, the concept of final services is often used to bring operational clarity to the priority setting and helps avoid double counting [36,37]. Final ESs are defined as "outputs of ecosystems ( ... ) that most directly affect the well-being of people and that retain a direct connection to the underlying ecosystem functions, processes and structures that generate them" [38]. The identification of a final service is flexible and depends on the stakeholders considered $[5,15]$, as well as on the purpose of the study [34]. For example, the pollination service can be considered a service for farmers, but it concurs with the production of fresh fruit and vegetables. In this case, farmers benefit from pollination and fresh fruit, but other citizens only benefit from fresh fruit. In the latter, pollination can be defined as an intermediate service, while the production of fresh fruit is a final service. If the focus is on landscape livability, it is important to work on final services and not on intermediate ones, as the selection of final services makes possible the quantification and spatial identification of the service users [33,39] that are located in the URs and comprise a key element to quantify livability.

Administrative areas are usually characterized by complex landscapes [40-42], and so, policy-makers need ES spatial accounting tools that can deal with this complexity in order to identify where to manage ESs. Existing spatial ES indicators often do not match policy maker's needs. This is largely due to a lack of indicators that quantify and connect service-providing areas (SPAs) with service benefiting areas (SBAs) through ecosystem service flow [8]. Actually, current indicators tend to concentrate on a single component of ES flow [3,14].

The pursuit of increasing landscape livability by local policy-makers can be achieved ensuring adequate levels of services to a population within their administered area. This means that measuring livability is strictly linked to understanding the degree of services in the SBAs and on the accessibility of SBAs from the URs. The degree of service in the SBAs depends on the service provided in the SPAs. In this light, the knowledge of the spatial relations between SPAs, SBAs and URs of each service is vital for effective management strategies, since they help to forecast the effect of the SPA management actions (consisting mainly of land use and land cover management), and so, to make livability-oriented decisions.

\section{Materials and Methods}

SOFA was developed based on a holistic case study [43] represented by the supra-municipal area of Perugia located in Umbria (Central Italy). This area, $1007 \mathrm{~km}^{2}$ wide, includes the municipalities of Perugia, Magione, Passignano sul Trasimeno, Corciano, Umbertide, Torgiano and Deruta (Figure 3). It is characterized by a complex, urban and productive landscape that, in the last few decades, has been deeply modified by high rates of urbanization, agricultural simplification and related rural transformations. Land use patterns in the area are very typical of Central Italy, consisting of $58 \%$ agricultural land, $28 \%$ forested and semi-natural land, $8 \%$ built-up land and less than $6 \%$ wetland and water bodies (CORINE Land Cover 2006, personal elaboration). The area is featured by various landscape types, including natural areas, as well as landscapes characterized by a high or medium incidence of arable lands, vineyards and olive yards; a large proportion of the study area is characterized by various mixed transitional landscapes [44]. In such heterogeneous areas, landscape planning proves to be highly challenging, as it involves addressing conflicting needs of the human populations living and working in the area (e.g., nature conservation, economic development, agricultural production, housing, etc.) and making it difficult to increase the general level of livability.

According to the stated research objectives, SOFA was developed in three consecutive steps: (1) selection of priority ESs and USs by objective criteria; (2) conceptualization and operationalization of spatial linkages between service-providing areas and service beneficiaries; and (3) elaboration 
of a scheme supporting the identification of the proper scale of required action and of the most appropriate actors.

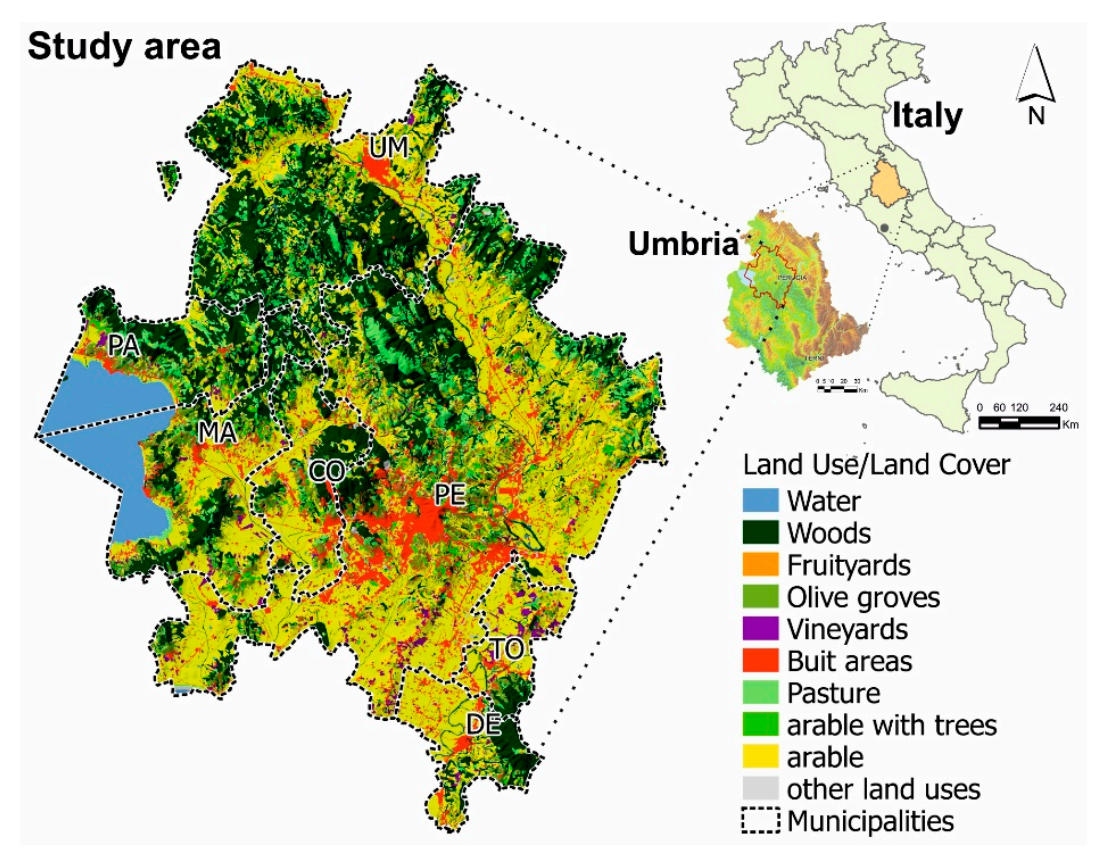

Figure 3. Location and land use/land cover of the study area. Chief towns of the municipalities: $\mathrm{CO}=$ Corciano, $\mathrm{DE}=$ Deruta, $\mathrm{MA}=$ Magione, $\mathrm{PA}=$ Passignano S.T., $\mathrm{PE}=$ Perugia, $\mathrm{TO}=$ Torgiano, $\mathrm{UM}=$ Umbertide.

\subsection{Selection of Priority Services}

Previous work by Antognelli and Vizzari [7] suggested a services classification based on CICES (Common International Classification of ESs) [38,45], integrated in a LIvability Assessment Model (LIAM), to include all services directly linked to place livability. Starting from this classification, an improved classification (called LIAM 2.0), including 53 final services, was developed in this research. To this aim, the local citizens were identified as the final beneficiaries of services, and various improvements were performed to achieve the final LIAM 2.0 classification. Firstly, 8 intermediate ESs were removed from the classification:

- "water from water distribution networks" producing services "1.1.5 groundwater for drinking" and "1.1.6 surface water for drinking";

- "hydrological cycle and water flow maintenance" producing services "1.1.5 groundwater for drinking" and "1.1.6 surface water for drinking" and of different regulation services;

- "storm and extreme climate phenomena protection" producing service "2.3.3 micro and regional climate regulation";

- "ventilation improvement" producing service "2.3.3 micro and regional climate regulation";

- "dilution by atmosphere, freshwater and marine ecosystems" producing service "2.3.5 maintenance of chemical condition of freshwaters by natural subsystem";

- "bioremediation by microorganisms, algae, plants and animals" producing services "2.3.5 maintenance of chemical condition of freshwaters by natural subsystem";

- "filtration, sequestration, storage, accumulation by ecosystems" producing service "2.3.5 maintenance of chemical condition of freshwaters by natural subsystem";

- "maintaining nursery populations and habitats" producing different services mainly related to agricultural production, such as "1.1.1 cultivated crop and algae" and "1.1.2 wild plants, algae and their outputs", but also to cultural services, such as "3.1.4 natural cultural heritage". 
In order to classify services according to the SPA type (human or natural, or mixed), 4 services were split into two separate services:

- "flood protection" became "2.1.1 buffering and attenuation of mass flows in river basins and flood protection by natural subsystem" and "2.1.2 buffering and attenuation of mass flows in river basins and flood protection by urban subsystem";

- "mass stabilization and control of erosion rates" became "2.1.3 mass stabilization and control of erosion rates by human subsystem" and "2.1.4 mass stabilization and control of erosion rates by natural subsystem";

- "mediation of smell/noise/visual impacts" became "2.2.1 mediation of smell/noise/visual impacts by natural subsystem" and "2.2.2 mediation of smell/noise/visual impacts by human subsystem";

- "buffering and attenuation of mass flows in river basins and flood protection" became "2.1.1 buffering and attenuation of mass flows in river basins and flood protection by natural subsystem" and "2.1.2 buffering and attenuation of mass flows in river basins and flood protection by human subsystem".

Moreover, 10 services were merged into 6 comprehensive services because they were barely represented in the study area, or produced by the same landscape component, or producing similar benefits for citizens:

- "cultivated crops" and "plants and algae from in situ aquaculture" were merged into service "1.1.1 cultivated crops and algae";

- "reared animals and their outputs" and "animals from in-situ aquaculture" were merged into service "1.1.3 reared animals from farming and aquaculture and their outputs";

- "fibers and other materials from plants, algae and animals for direct use or processing" and "materials from plants, algae and animals for agricultural use" were merged into service "1.2.1 fibers and other materials from plants, algae and animals for direct agricultural or diverse use or processing";

- " "agro-natural environment with sacred and/or religious values" and "agro-natural environment with symbolic value" were merged into "3.3.1 sacred or symbolic values of natural subsystem";

- "buffering and attenuation of mass flows in river basins" and "flood protection" became "buffering and attenuation of mass flows in river basins and flood protection", which was recently split into two services based on the source type (human or natural subsystem).

Since the divisions were not meant to represent the SPA type, "Services for spiritual, symbolic and other interactions with agri-natural elements and land/seascapes" was merged with division "Services for spiritual, symbolic and other interactions with the built environment and land- or sea-scapes" in division "3.3 Services for spiritual, symbolic and other interactions with agri-natural elements".

The definition of the study area made it possible to exclude some other services, based on the typical services scale and the managed area. As the classification aims at including only the services directly manageable for increasing landscape livability, we included only those services whose SBA can be spatialized in the study area. In this light, service "2.3.2 chemical conditions of salt waters" was eliminated. Moreover, we excluded from LIAM 2.0 those services for which UR cannot be spatially identified. To do this, we interpreted the demand type of each service based on Wolff et al. [39] and considered the components of the basic infrastructure systems [46]. In this regard, we characterized 3 types of spatial relationships-overlaying, not overlaying or undefined-between SBAs and URs, which helped to define the typical UR scale of the services benefiting the study area. Then, 3 services whose relationship between URs and SBAs was undefined (because the service is delivered by a number of different SAAs) were eliminated from the classification:

- 2.3.6 global climate regulation by reduction of greenhouse gas concentrations; 
- $\quad$ 3.3.1 possibility of bequest of the natural environment for the future generations);

- 3.3.2 perception of existence of natural elements value;

Finally, to make the classification more coherent, some services were renamed:

- "1.3.4 energy from distribution networks" was renamed "1.3.4 energy from fossil fuels";

- "2.3.3 pest and disease control" was renamed "2.3.1pest and disease control by natural subsystem";

- "2.3.1 chemical condition of freshwaters" was renamed "2.3.5 maintenance of chemical condition of freshwaters by natural subsystem";

- "2.2.3 degradation, decomposition or mineralization of pollutants by wastewater collecting systems and water treatment plants" was renamed "2.3.6 maintenance of chemical condition of freshwaters by human subsystem";

- "3.1.1 aesthetic" was renamed "3.1.1 landscape aesthetic";

- "3.4.1 urban spiritual services" was renamed "3.3.2 sacred or symbolic values of human subsystem";

- "4.1.4 urban transport service" was renamed "4.1.4 public transport service".

\subsection{Operationalization of Spatial Linkages between SPAs and URs}

A literature review of ESs' and USs' spatial dynamics, supported by empirical observations, allowed collecting information about the spatial configuration of each single service included in the classification. In particular, some studies about the general spatial dynamics of ESs [30,47] and USs [48] and others dealing with specific services [49-51] helped to identify service spatial linkages and to build a general framework useful to understand the spatial behavior of services and the characterization of their providing area. To support the applicability of these concepts to other study areas, an operational flow diagram was built organizing and synthesizing the informative content of the service spatial models and of the concepts emerging from the study in a usable way for policy-making.

\subsection{Identifying Scale of Required Action and Most Appropriate Actors}

Evidence shows that the study area benefits from services produced either inside and outside, so, we classified each service (on the basis of its SPAs) into externally or internally produced, relative to the area, as suggested by [52]. This classification is based on the typical service scale [53] and the economic organization of the study area, which can be local when the study area benefits only from the SPAs included, or regional, when the area of interest can benefit also from the SPAs produced around it. In order to give useful information to policy-makers, the resulting information were synthesized and combined in a visual scheme designed for the identification of the proper scale of required action and the most appropriate actors. The synthesis could be applied to extend the SPA characterization to other service classifications and other study areas.

\subsection{Application to Case Studies}

Finally, the whole methodology was tested through the application on two example cases. In the first case, SOFA was applied for comparing different complementary or substituted services answering to the same need. The objective was to show how the suggested framework of analysis can be used for defining appropriate service indicators for different decisions. In the second case, a real case study was used to show the method's effectiveness in identifying the sectoral policy, the authorities involved and the land use-land cover to change for solving a concrete problem, namely increasing the water quality of a water stream.

\section{Results}

\subsection{The LIAM 2.0 Classification}

The selection of priority services resulted in the new LIAM 2.0 classification (provided in Table S1 of the Supplementary Material) including a total of 53 services (16 provisioning, 12 regulating, 11 cultural and 
14 social services). It contains 15 services less than the original LIAM classification from which it derives. Despite the range of needs met by the services in the two classifications being the same, LIAM 2.0 includes 23 USs (one more than LIAM), but only 30 ESs (14 less than LIAM). Each service in the classification was explicitly characterized by a number of attributes based on the various concepts described in this study (demand type, SPA type, spatial model type, SAA type).

\subsection{Spatial Linkages between SPAs and URS}

The literature review and empirical observations on service demand resulted in the characterization of three types of spatial relationships between SBAs and URs:

- Overlaying: Services desired for risk reduction [39] are produced and delivered by natural ecosystems and man-made structures, sometimes interacting. These services cannot be moved from the place where they are delivered as they are delivered to consumers without the need to be accessed, and therefore, their SBA usually overlaps with their UR. Some services that are used directly (e.g., water, energy) are delivered in the URs by the basic infrastructures [46], meaning that their delivery has to be ensured to each urban building or settlement. For these services, the SAA cannot be identified;

- Not overlaying: This spatial linkage is typical of services that are used directly. This demand type characterized provisioning services (mainly goods such as food and materials) and some cultural services (e.g., physical interaction with landscape for recreational purposes). They are delivered far away from the potential consumers, so that the SAA is typically constituted by roads and paths for the physical accessibility of the SBA.

- Undefined: Some services commonly identified in ES classifications such as bequest, existence and carbon dioxide reduction, as well as some ex situ cultural services, such as the production of books and documentaries about a heritage site (see, e.g., [38]), are commonly preferred. In these case, the definitions of the SBA and UR are often not univocal, and the UR is not related to a defined area, but is potentially spread all over the world. Therefore, preferred services are delivered globally. For this reason, as explained, they were also excluded from the LIAM 2.0 classification. For these services, the service access area cannot be physically identified.

The elaboration of concepts emerging from the literature review about service spatial dynamics, together with literature review and empirical observations about single services, resulted in five models and ten sub-models of spatial relationships between SPAs, SBAs and URs (Table 1).

In Models 1 and 2, SBA and UR do not overlay, meaning that SBA have to be accessed to use the service, and SPA and SBA do not overlay either. Model 1A is typical of local ecosystem services or local agricultural services, while Model 1B is typical of multiscale agricultural services and multiscale urban services. All the services included in this model, except landscape aesthetics, are consumed goods. Since these services can be moved across space, their SBAs can differ from SPA and UR. Moreover, all these services are produced by agricultural activity. The SCA in Model 1 is usually the road network, except for the aesthetic services, that flows along lines of sight, while the SAA is usually the transportation network.

In Model 2, SPA overlays SBA, but accessibility to the SBA is needed and takes place by the transportation network. The considered SBA (and consequently the SPA) can be internal to the study area (Model 2A) or external (Model 2B). Model 2 is typical of the directly used services, which can be produced by either biophysical or socioeconomic subsystems, sometimes interacting. 
Table 1. Empirical models of the spatial relationships between Service-Providing Areas (SPAs), Service Benefiting Areas (SBAs) and Use Regions (URs) of services included in the classification. For each model, a representative service and its spatial flow components, including Service Connecting Areas (SCAs) and Service Access Areas (SAA) (see Figure 2), are reported. Green arrow: service production flow, orange arrow: accessibility; $\neq$ : not overlaying; $\subset$ : included into; $=$ : overlaying.

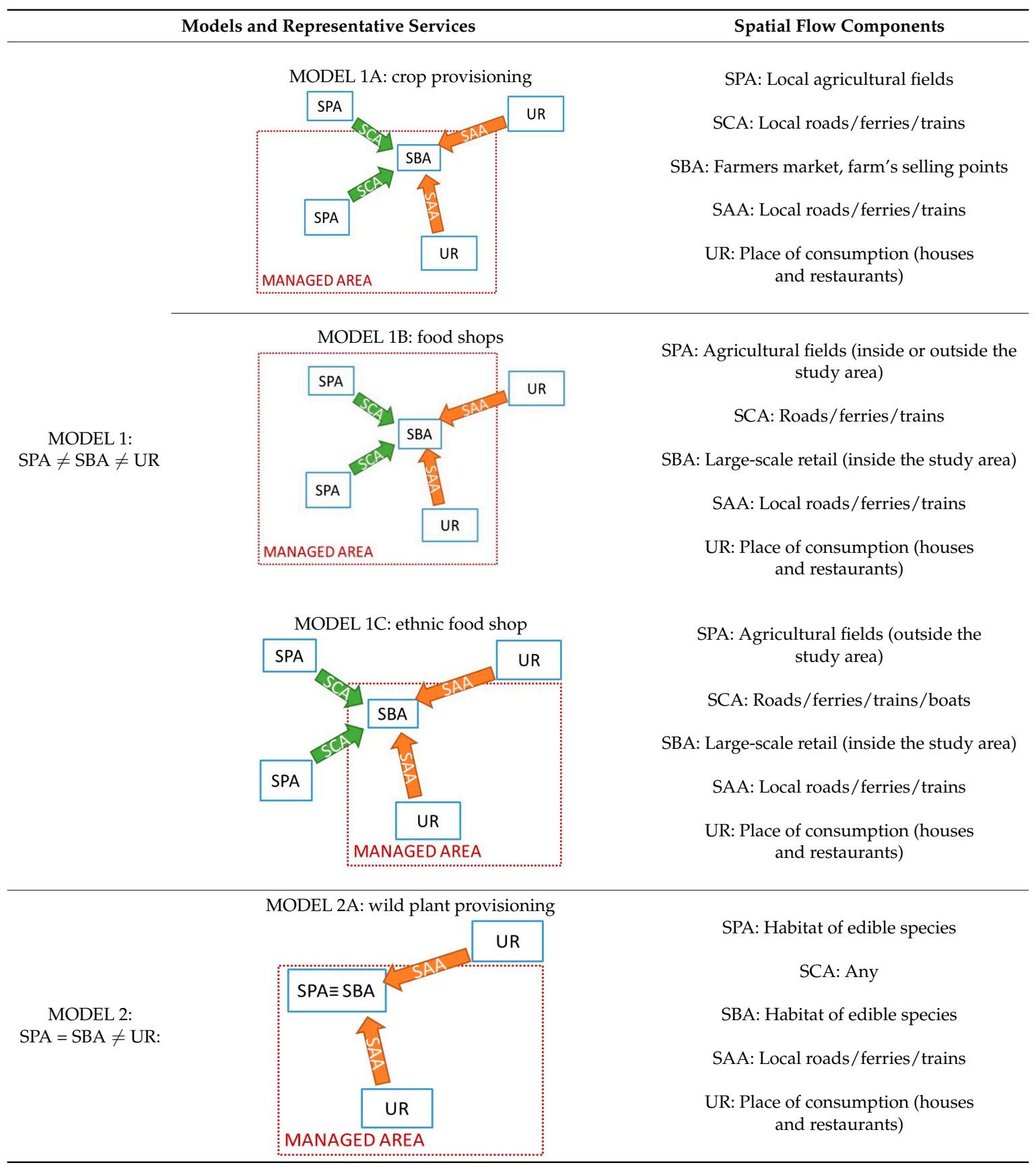


Table 1. Cont.

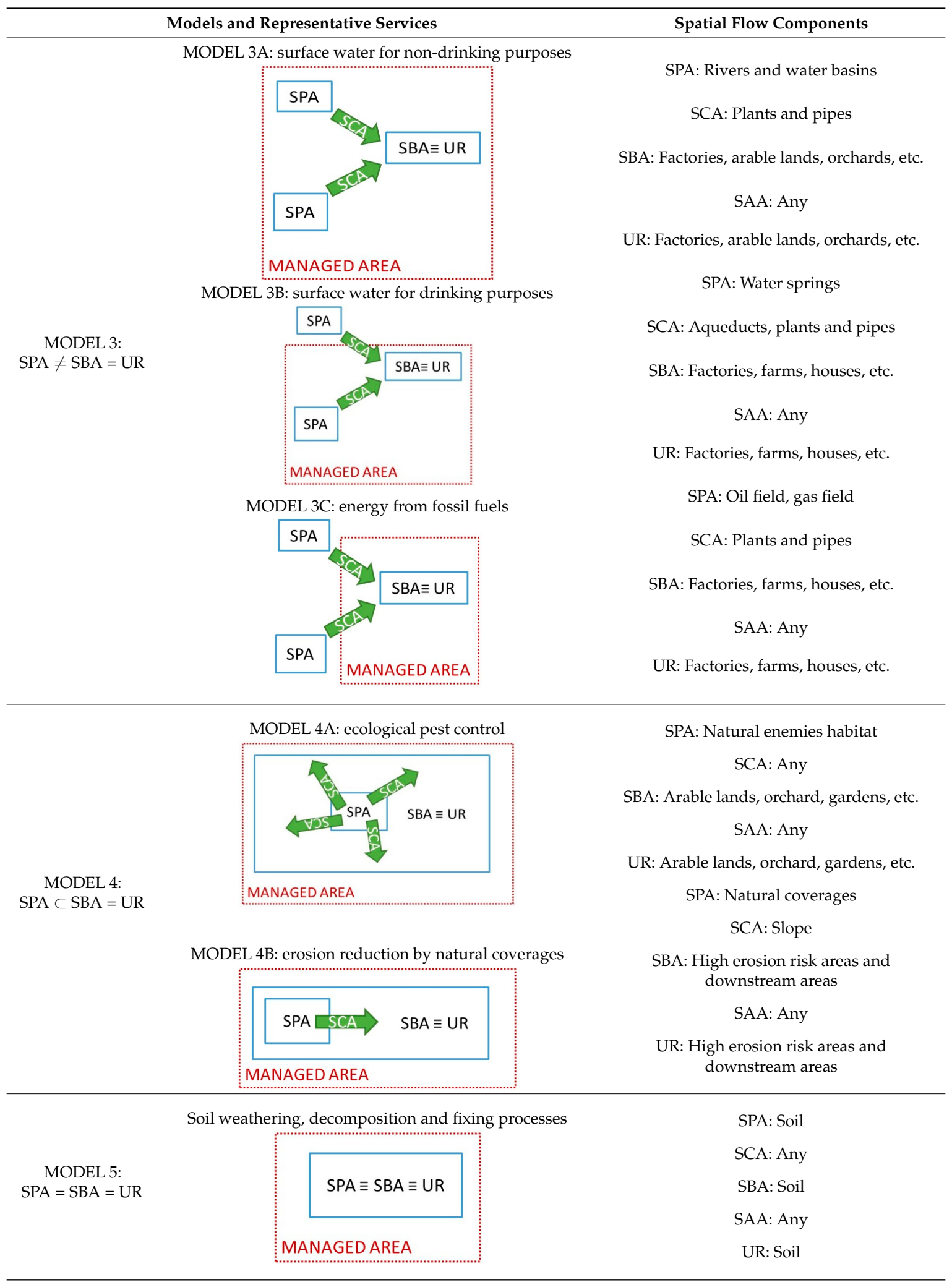

Model 3 represents basic urban infrastructures (energy, drinking water, etc.) and two regulating services related to the maintenance of water quality. The services described by this model are mainly produced by the biophysical subsystem (e.g., water springs) sometimes interacting with the socioeconomic subsystem (e.g., for the animal energy resources). The SPA can be internal, partially 
internal or external to the study area depending on the local availability of SPA, on the organization of the socioeconomic subsystem and on the dimension of the study area. The SCAs are represented by pipes and plants or, rarely, by soils (slopes).

Model 4 is typical of risk reduction services, which, from the SPAs perspective, can be produced by natural or mixed human-natural SPAs. The SCAs are natural elements such as soil, air and water.

Model 5 represents in situ services [15,34]. This includes services produced by natural and/or urban SPAs.

The operational flow diagram synthesizes in a usable way for policy-making the described spatial relationships between SPAs and URs, the information deduced from the literature review and empirical observation of the services (Figure 4).

\begin{tabular}{|c|c|c|c|c|c|c|c|c|c|c|c|}
\hline \multirow[t]{2}{*}{1} & \multirow[t]{2}{*}{ Relation SPA - SBA } & \multicolumn{4}{|c|}{ Not overlaying (*1.1) } & \multicolumn{6}{|c|}{ Overlaying (*1.2) } \\
\hline & & \multicolumn{4}{|c|}{1} & \multicolumn{6}{|c|}{ I! } \\
\hline \multirow[t]{2}{*}{2} & \multirow[t]{2}{*}{ Relation SBA-UR } & \multicolumn{3}{|c|}{ Not overlaying $\left({ }^{*} 2.1\right)$} & $\begin{array}{l}\text { Overlayin } \\
\mathrm{g}(* 2.2)\end{array}$ & \multicolumn{3}{|c|}{ Not overlaying $(* 2.3)$} & \multicolumn{2}{|c|}{$\begin{array}{l}\text { Partially overlaying } \\
\qquad\left({ }^{*} 2.4\right)\end{array}$} & $\begin{array}{c}\text { Overlayin } \\
\mathrm{g}\left({ }^{*} 2.2\right)\end{array}$ \\
\hline & & \multicolumn{3}{|c|}{1} & 1 & \multicolumn{3}{|c|}{ 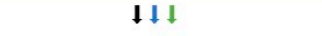 } & \multicolumn{2}{|c|}{ I } & I \\
\hline & \multirow[t]{2}{*}{ MODEL } & \multicolumn{3}{|c|}{ MOD 1} & MOD 2 & \multicolumn{3}{|c|}{ MOD 3} & \multicolumn{2}{|c|}{ MOD 4} & MOD 5 \\
\hline & & I & 1 & 1 & 1 & I! & 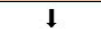 & 1 & $I$ & $\downarrow$ & $I$ \\
\hline \multirow[t]{3}{*}{3} & \multirow[t]{2}{*}{$\begin{array}{l}\text { Relation SPA - } \\
\text { ADMINISTRATIVE AREA }\end{array}$} & $\operatorname{lnt}(* 3.1)$ & $\begin{array}{l}\text { Partially } \\
\text { int }(* 3.2)\end{array}$ & Ext $(* 3.3)$ & $\operatorname{lnt}(* 3.1)$ & $\operatorname{lnt}(* 3.1)$ & $\begin{array}{l}\text { Partially } \\
\text { int }(* 3.2)\end{array}$ & Ext $(* 3.3)$ & $\begin{array}{c}\text { Undirectio } \\
\text { nal (int) } \\
\left({ }^{*} 3.1\right)\end{array}$ & $\begin{array}{l}\text { Directiona } \\
\text { I (partially } \\
\text { int) }\left({ }^{*} 3.2\right)\end{array}$ & Int $(* 3.1)$ \\
\hline & & I & 1 & I & 1 & I! & I & I & I & I & I \\
\hline & SUBMODEL & $1 \mathrm{~A}$ & $1 \mathrm{~B}$ & $1 \mathrm{C}$ & $2 A$ & $3 A$ & 3B & $3 C$ & $4 \mathrm{~A}$ & $4 B$ & $5 A$ \\
\hline
\end{tabular}

Figure 4. Flow diagram for the identification of the service spatial models and sub-models (in orange). Information supporting policy-making derived from spatial models (in brackets): 1.1 SAA: transport services; 1.2 no SAA, basic urban infrastructure or risk reduction services; 2.1 SCA: transport network; 2.2 no SCA; 2.3 SCA: pipes and plants (or slope); 2.4 SCA: natural elements (air, water, soil); 3.1: management at local scale (local authorities or local privates); 3.2: management at broader scales (interaction between local authorities); 3.3: no possibility of management by local authorities; Blue and green arrows refer to the services 2.3.6 (maintenance of chemical condition of freshwaters by socioeconomic subsystem") and 2.3.5 ("maintenance of chemical condition of freshwaters by biophysical subsystem"), tools for the selection of scales of required actions and most appropriate actors.

\subsection{Scales of Required Action and Most Appropriate Actors}

To complement the flow diagram, the literature review about single services supported the identification of different types of SPAs, based on the relation of the typical SPA scale within the study area and on the subsystems that produce the services (see Table S1). This step generated nine categories supporting the identification of the proper scale of required action and the most appropriate actors (Figure 5).

Four of the service types are "endpoint" service types: local ESs, local USs, global or external ESs and global or external USs. The interaction of the socioeconomic subsystem and the biophysical subsystem outside the study area can also generate external agricultural services, such as food produced completely outside the study area. Multiscale USs, such as the provision of fossil fuels, are highly dependent on internal urban SPAs, such as roads and manufacturers, and on external socioeconomic subsystem elements, such as factories, rails, roads, etc. Multiscale ESs are typically regulating services produced at a similar scale (but not coincident) as the administrative boundary considered, such as seed rape pollination at the farm scale [54] or flow regulation at the municipality scale. Multiscale agricultural services are the product of agricultural activity [5]. For example, the delivery of crop products in supermarkets depends on both local agricultural systems and external agricultural systems, and the agricultural systems are the result of a close human-natural 
interactions. The interaction between human and biophysical subsystems in the study area generates local agricultural services, such as in case of the local production of crops. The same interaction can take place outside the study area generating external agricultural services.

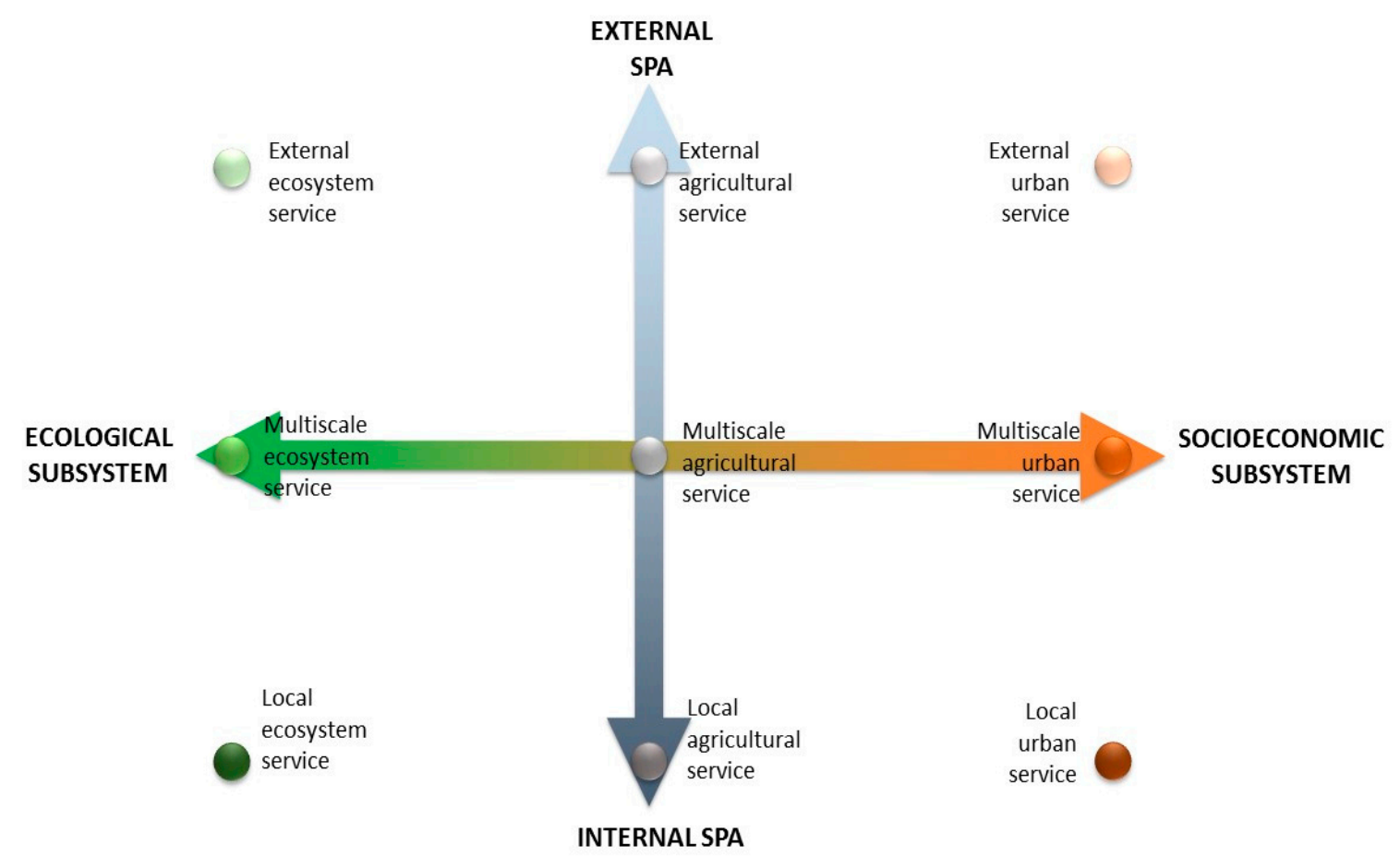

Figure 5. Classification of ESs' and USs' delivery points in a study area based on the SPA typology.

The observation of the number of services, cross-tabulated per SPA type, demand type and need of accessibility of different services, gives useful insights into relation between the final service users (located in the use region) and the SPA of the services included in LIAM 2.0 (Table 2). The number of services by demand and SPA type shows that our classification includes few external services, while the majority are local ones. It also shows that, contrary to ESs, the majority of USs require accessibility. Moreover, as previously explained, services for risk reduction do not require accessibility, while consumed and directly-used services can require accessibility to give benefits to citizens. Moreover, the information reported in the Supplementary Material confirms that the consumed services that do not need accessibility are basic urban infrastructures.

Table 2. Classification and number of services in each demand (rows) and SPA (columns) type. ASs = agricultural services.

\begin{tabular}{|c|c|c|c|c|c|c|c|c|c|}
\hline & $\begin{array}{l}\text { External } \\
\text { ESs }\end{array}$ & $\begin{array}{l}\text { External } \\
\text { USs }\end{array}$ & $\begin{array}{l}\text { Local } \\
\text { ASs }\end{array}$ & $\begin{array}{l}\text { Local } \\
\text { ESs }\end{array}$ & $\begin{array}{l}\text { Local } \\
\text { USs }\end{array}$ & $\begin{array}{c}\text { Multi-Scale } \\
\text { ASs }\end{array}$ & $\begin{array}{l}\text { Multi-Scale } \\
\text { ESs }\end{array}$ & $\begin{array}{l}\text { Multi-Scale } \\
\text { USs }\end{array}$ & Total \\
\hline $\begin{array}{l}\text { Accessibility } \\
\text { not needed }\end{array}$ & & 1 & 3 & 8 & 3 & & 5 & 2 & 22 \\
\hline Consumption & & 1 & 3 & 1 & & & 3 & & 8 \\
\hline Direct use & & & & & 2 & & & & 2 \\
\hline Risk reduction & & & & 7 & 1 & & 2 & 2 & 12 \\
\hline $\begin{array}{l}\text { Accessibility } \\
\text { needed }\end{array}$ & 1 & 1 & 5 & 6 & 15 & 3 & & & 31 \\
\hline Consumption & & & 3 & 3 & & 2 & & & 8 \\
\hline Direct use & 1 & 1 & 2 & 3 & 15 & 1 & & & 23 \\
\hline Total & 1 & 2 & 8 & 14 & 18 & 3 & 5 & 2 & 53 \\
\hline
\end{tabular}




\subsection{Application of the Framework in Example Cases}

\subsubsection{Case I: Comparing Complementary or Substituted Services}

The identification of the service spatial model supported the comparison of different services to find a suitable indicator type for targeted and effective decision-making (Table 3). In fact, depending on the purpose of the application, a different way of spatializing services should be used. For example, in comparing services meeting the same human need (e.g., foods), the purpose of the comparison (e.g., making decisions about the management of the SPA, rather than understand the availability of substituted or complementary services in the study area) determines the choice of different areas to which refer the different spatial indicators quantifying the provision or demand of services.

Table 3. Comparison of possible locations to which refer indicators of the different spatial aspects of food provisioning services flows applying the LIAM 2.0 spatial models. SPA = Service Providing Areas, $\mathrm{SCA}=$ Service Connecting Areas; SBA = Service Benefiting Areas; SAA = Service Access Areas.

\begin{tabular}{ccccc}
\hline Service & 1.1.7 Food from Shops & $\begin{array}{c}\text { 1.1.3 Reared Animals } \\
\text { from Farming }\end{array}$ & $\begin{array}{c}\text { 1.1.1 Cultivated } \\
\text { Crops }\end{array}$ & $\begin{array}{c}\text { 1.1.2 Wild Plants, Algae and } \\
\text { Their Outputs }\end{array}$ \\
\hline Model & Model 1B & Model 1A & Model 1A & Model 2A \\
\hline SPA & $\begin{array}{c}\text { Multiscale agricultural service: } \\
\text { agricultural fields located in the } \\
\text { arket are produced. This is quite } \\
\text { different to identify, because it varies } \\
\text { based on the product considered. In } \\
\text { this case, the map should extend } \\
\text { outside the study area }\end{array}$ & $\begin{array}{c}\text { Local agricultural service: pastures } \\
\text { and cowsheds of local farms selling } \\
\text { animal products locally }\end{array}$ & $\begin{array}{c}\text { Local agricultural } \\
\text { service: } \\
\text { agricultural fields } \\
\text { of local farms } \\
\text { selling vegetable } \\
\text { products locally }\end{array}$ & $\begin{array}{c}\text { Local ecosystem service: } \\
\text { edible plant habitats }\end{array}$ \\
\hline SCA & Transport network & Transport network & Transport network & Any \\
\hline SBA & Food shops & Farms & Farms & Roads and \\
\hline SAA & Roads and transport networks & Roads and transport networks & Roads and transport networks \\
\hline UR & Residential areas & Residential areas & Residential areas & Residential areas \\
\hline
\end{tabular}

If the purpose of the application is quantifying the service produced, then quantification should be performed in their SPAs, while if the purpose of the application is quantifying the service benefiting people, SBAs should be used for localizing the indicator, and finally, if the interest is to map the demand, then residential areas should be mapped (Table 3). The reported observations are also important to define the most appropriate decision-maker for managing the service, since it identifies the most appropriate scale and policy that have an effect on the SPAs, and so, on the quantity of service provided.

\subsubsection{Case II: Increasing the Water Quality of a Water Stream}

To demonstrate the operative usability of SOFA for decision-making, we apply the flow diagram to a real case study (Figure 6), supplemented with the other information supplied with the LIAM 2.0 classification (see Table S1). This shows how the flow of information retrieved from the flow diagram can be interpreted in a useful way for decision-makers. The case study considers a village that is allowed by its municipality to dispose wastewater in the water stream (Figure 6). As river water is also used for agricultural (and recreation) purposes, a conflict clearly arises. LIAM 2.0 classification suggested that two services can meet the same need: "maintenance of chemical condition of freshwaters by socioeconomic subsystem" or "maintenance of chemical condition of freshwaters by biophysical subsystem", which may mean the improvement of natural resources for filtering water (for example by wooded vegetation strips) or of urban infrastructures (for example a depurator). Therefore, the policy maker can decide which of the two services increase. Looking at the map (Figure 6), it seems clear that the SPAs do not overlay SBAs, while SBAs overlay URs. These observations make it possible to apply SOFA tools. 


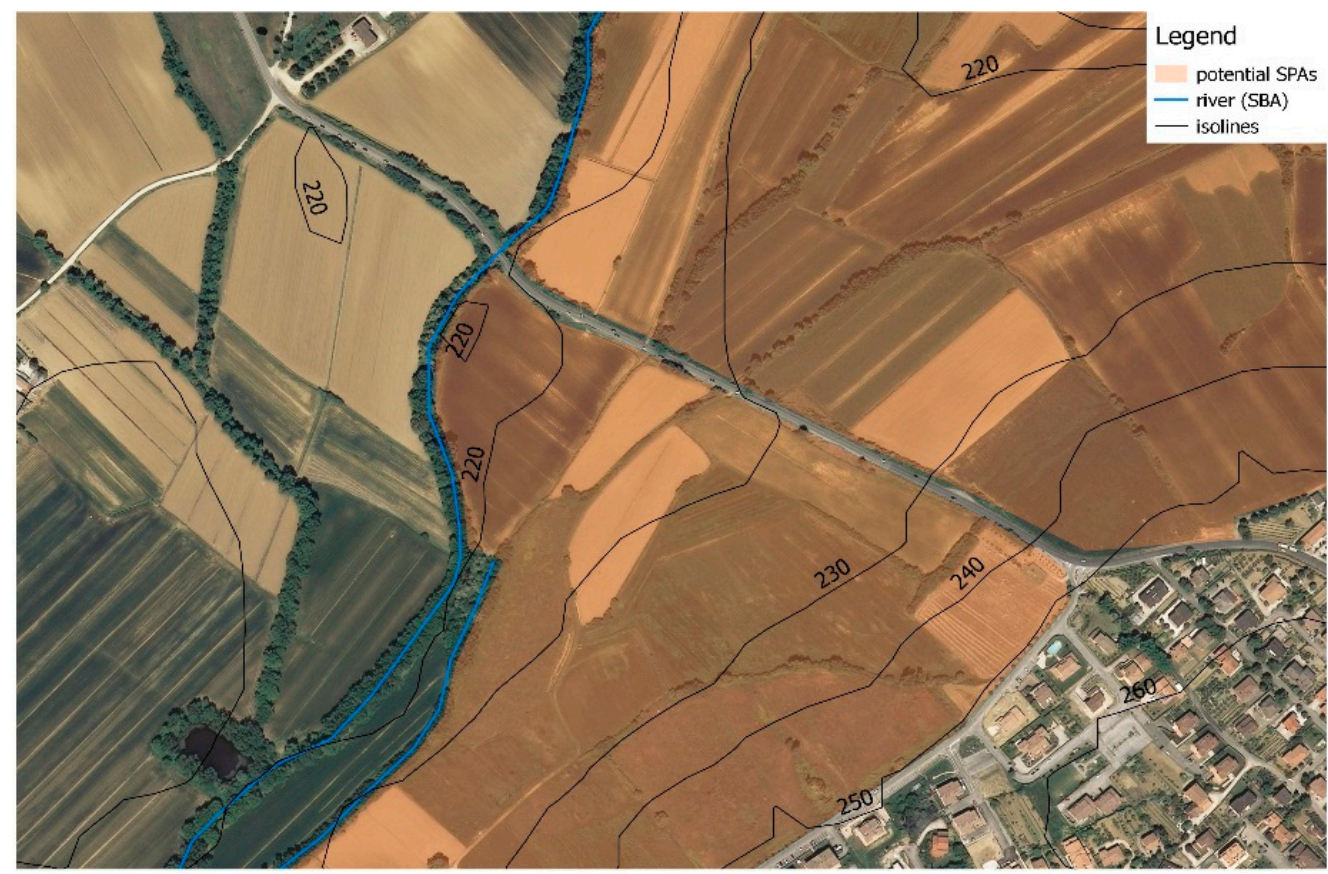

Figure 6. Identification of the SBA (the river, in blue) and the SPA (the agricultural area, in orange) for the provisions of services "maintenance of chemical condition of freshwaters by socioeconomic subsystem" or "maintenance of chemical condition of freshwaters by biophysical subsystem" in a local context within the study area.

Applying the two SOFA tools (the flow diagram of Figure 4 and the SPA classification of Figure 5), it is possible to highlight that the service follows Model 3A. Moreover, as SBA is internal to the administrative area, these services (2.3.6 and 2.3.5 respectively) are both characterized by Model 3A. The services 2.3.5 and 2.3.6 meet the same need in a very different manner, since they are produced by different subsystems. In fact, their SPA type is different. Synthesizing the information reported in the caption of the flow diagram (Figure 4) with the information about SPA (Figure 5), it is possible to retrieve the information reported in Table 4.

Table 4. Comparison of the management information about possible services for the maintenance of the chemical conditions of freshwater applying the SOFA tools.

\begin{tabular}{|c|c|c|}
\hline Service & 2.3.5 (Green Arrows and in Figure 4) & 2.3.6 (Blue Arrows and in Figure 4) \\
\hline Model & Model 3A & Model 3A \\
\hline SPA & $\begin{array}{l}\text { Local ecosystem service-managed at the } \\
\text { local scale }\end{array}$ & $\begin{array}{l}\text { Local urban service-managed at the } \\
\text { local scale }\end{array}$ \\
\hline SCA & Pipes and plants or slope & Pipes and plants or slope \\
\hline SBA & Internal-managed at the local scale & Internal-managed at the local scale \\
\hline SAA & - & - \\
\hline UR & Internal-managed at the local scale & Internal-managed at the local scale \\
\hline
\end{tabular}

With this, the framework supports the identification of the administrative area that can manage the service, and the most appropriate regulation. In fact, the service 2.3.6 ("maintenance of chemical condition of freshwaters by socioeconomic subsystem") is provided by a man-made SPA, and so, it should be managed by urban regulations; while the service 2.3.5 ("maintenance of chemical condition of freshwaters by biophysical subsystem") is provided by the natural SPAs, and so, it can be managed by the regulation of natural resources. These considerations may help to choose the best technical solution, considering that benefiting the SBA means improving SPA. 


\section{Discussion}

SOFA is an operational framework aimed at supporting decision-making through simple concepts and tools that support the integration of ESs and USs in policy making. Previous studies already suggested methodologies for the integration of the ES concept in policy-making. For example, some approaches suggested managing ESs at the landscape scale by managing land use change scenarios, considering that the services availability is the result of the presence of defined land uses (see, e.g., $[55,56])$. Other studies suggested more specific approaches for single ES management (see, e.g., [32,57]) that support service-specific decision-making. However, all these approaches focused only on supporting decisions about ESs, but none of them considered the management of USs. Our framework differs from such approaches by providing relatively specific information about each single service, for a reasonably high number of services. Moreover, it gives the same information for both ESs and USs, helping the decision-makers to choose the best option for going towards the satisfaction of population's needs. Thus, the proposed approach can support the identification of the possible available solutions. However, the results of the application on increasing the water quality of a river highlight that the information given by SOFA should be integrated with the skills and experience of different decision-makers in the various sectors to compare the possible technical solutions to increase the provisioning of different services.

SOFA uses the improved LIAM 2.0 classification, which appears simpler and more effective for livability analysis than the previous LIAM classification, as it responds to the requirements expressed by Antognelli and Vizzari [17]. The analysis of the relationships between URs and SBAs highlighted that the different relationships between them are typically associated with services with well-defined characteristics that help to interpret the SAAs connecting URs to SPAs. These models go beyond those previously suggested [30,34] for two main reasons: (1) they are designed for ESs, as well as USs; and (2) they separate and identify the different spatial processes composing the service flow (from SPAs to SBAs and from URs to SBAs), giving a coherent and analytical methodology for the interpretation of the service spatial flow.

The 53 LIAM 2.0 services investigated to identify spatial models originates only five models and 10 sub-models. As the LIAM 2.0 services represent a consistent case study, where the majority of services to manage for enhancing landscape livability at the scale of analysis are included, it is possible to observe that the five models represent the majority of the possible spatial relationships between SPA, SBA and UR that a policy-maker can manage for enhancing livability. Contrarily, the sub-models of Models 1, 2, 3 and 5, differentiated considering the spatial relationships of the different services with the study area, are valid in the identified case study, but they should be validated in other cases, because they might be varied depending on the dimension of the study area and on its economy. In fact, despite being developed for a specific area, SOFA can be extended to different study areas and to different service classifications simply following the suggested methodological steps.

The nine classes in which the SPAs were characterized appear clearly useful for supporting landscape planners in making decisions about how to manage the services. In detail, they help to define which sectoral policy can best manage the service and highlight if there is a possibility for policy-makers to manage the service at the study area scale. These two aspects are usefully analyzed together as the degree of autonomy of the local authorities can be different for different sectoral policies, meaning that, for example, the administration of local ecosystem services might be more dependent on European, national and regional policies than local urban services. In this light, considerations about different opportunities to meet the needs of inhabitants, and so increase livability, may help to find out the most technically and politically feasible management action at the scale that results in being more appropriate for increasing services to meet a defined need.

The application of the framework for solving concrete decision-making problems (choosing a service indicator or increasing wastewater of a stream) demonstrates that this approach is able to give useful information to policy-makers for a more accurate service management. In the first case, it supported the spatialization of quantitative data about the service based on the purpose of the decision. This means that it does not support the identification of the service attribute to quantify, 
which can vary based on the study purpose and data availability [58], but only helps to identify the location of the service. In the second case, the approach revealed its utility in organizing empirical and objective information about services that can support decision-making at a defined scale. The results should be compared with the current regulations to identify limitations and synergies for services management for each authority that could eventually manage the service. This comparison could also give interesting views on the regulations that define the proper management authority for each service.

Mckenzie et al. [59] explained that ecosystem services knowledge can be integrated into policy-making at the local scale with three different aims: policy-makers can use knowledge conceptually, strategically or instrumentally. In the first case, the ecosystem services knowledge helps to raise the environmental awareness of policy-makers and other stakeholders. In the second case, it legitimates choices or explains decisions, and in the third case, it influences the political choice, i.e., helping to decide among options. In this regard, SOFA substantially supports the three uses of ES knowledge, since it shows that ESs are able to meet human needs comparably to USs, raising public awareness about ESs. Moreover, the framework helps to legitimate the choice for meeting human needs by implementing ESs instead of USs in specific cases.

\section{Conclusions}

SOFA, developed in this research, is an operational framework for a better integration of ESs and USs into policy-making. The framework includes an improved and more specialized ES and US classification (LIAM 2.0) able to support decision-making about livability services more effectively. The study revealed that the wide range of services included in LIAM 2.0 can be easily framed into five models and 10 sub-models showing typical and identifiable service access and connecting areas. A flowchart, synthesizing the logical steps for identifying the service spatial model, was developed, based on common empirical observations. It resulted in a practical guide for supporting the identification of the flow model of different services to be applied and validated also in other study areas. The study characterized the SPAs of each service included in the classification to support the identification of effective sectoral policies, while, at the same time, offering an intersectoral operational framework supporting decisions for increasing landscape livability.

The flowchart, together with demand and SPAs characterization, proved to be useful also to compare possible technical solutions for solving defined problems, because it not only gives information about the spatial relationships between SPAs, SBAs and URs, but also additional information about the providing areas and the sectoral policy that could manage services. In this view, SOFA can support the integration of ESs in policy-making since it allows the comparison of nature-based solutions with human-based ones. The classification could also be adapted to other study areas, where the whole framework can be applied thanks to the SPA classification scheme and the flowchart.

SOFA recognizes ESs as important as USs, overcoming the traditional dualism between ecosystem services and urban amenities and enlarging the concept of place livability and its related concept of well-being. This supports a better identification of the possible solutions by considering and evaluating both urban and ecosystem services, overcoming the traditional dualism about natural resource conservation and economic development.

Supplementary Materials: The following are available online at http:/ /www.mdpi.com/2071-1050/10/4/1017/ s1, Table S1: LIAM 2.0 service classification in MS Excel format, including demand, source, spatial models and economic type characterization for each service.

Acknowledgments: This research was developed within the framework of the TRUSTEE (Towards RUral Synergies and Trade-offs between Economic development and Ecosystem services) project funded by the RURAGRI ERA-NET Consortium, which includes the Italian Ministry of Agricultural, Food and Forestry Policies.

Author Contributions: All the Authors conceived the research. Sara Antognelli and Catharina J. E. Schulp designed the methodology; Sara Antognelli applied the methodology and analyzed the data; Catharina J. E. Schulp and Marco Vizzari supervised the research; all the Authors wrote the paper.

Conflicts of Interest: The authors declare no conflict of interest. 


\section{References}

1. $\mathrm{Wu}, \mathrm{J}$. Landscape sustainability science: Ecosystem services and human well-being in changing landscapes. Landsc. Ecol. 2013, 28, 999-1023. [CrossRef]

2. Maslow, A.H. Motivation and Personality; Harper \& Row: New York, NY, USA, 1954.

3. Wolff, S.; Schulp, C.J.E.; Kastner, T.; Verburg, P. Quantifying spatial variation in ecosystem services demand: A global mapping approach. Ecol. Econ. 2016. [CrossRef]

4. Modica, G.; Zoccali, P.; Di Fazio, S. The e-Participation in Tranquillity Areas Identification as a Key Factor for Sustainable Landscape Planning. In Lecture Notes in Computer Science, Proceedings of the Computational Science and Its Applications, ICCSA 2013, Ho Chi Minh City, Vietnam, 24-27 June 2013; Murgante, B., Misra, S., Carlini, M., Torre, C., Nguyen, H.-Q., Taniar, D., Apduhan, B., Gervasi, O., Eds.; Springer: Berlin, Germany, 2013; Volume 7973, pp. 550-565.

5. Landers, D.H.; Nahlik, A.M. Final Ecosystem Goods and Services Classification System (FEGS-CS); EPA: Washington, DC, USA, 2012.

6. Vitousek, P.M.; Mooney, H.A.; Lubchenco, J.; Melillo, J.M. Human Domination of Earth's Ecosystems. Science 1997, 277, 494-499. [CrossRef]

7. Antognelli, S.; Vizzari, M. Ecosystem and urban services for landscape liveability: A model for quantification of stakeholders' perceived importance. Land Use Policy 2016, 50. [CrossRef]

8. Baró, F.; Palomo, I.; Zulian, G.; Vizcaino, P.; Haase, D.; Gómez-Baggethun, E. Mapping ecosystem service capacity, flow and demand for landscape and urban planning: A case study in the Barcelona metropolitan region. Land Use Policy 2016, 57, 405-417. [CrossRef]

9. De Montis, A.; Reggiani, A. Cities; Pergamon Press: Oxford, UK, 2013; pp. 1-3.

10. Howley, P. Attitudes towards compact city living: Towards a greater understanding of residential behaviour. Land Use Policy 2009, 26, 792-798. [CrossRef]

11. Leby, J.L.; Hashim, A.H. Liveability Dimensions and Attributes: Their Relative Importance in the Eyes of Neighbourhood Residents. J. Constr. Dev. Ctries 2010, 15, 67-91.

12. Hein, L.; Van Koppen, K.; de Groot, R.S.; Van Ierland, E.C. Spatial scales, stakeholders and the valuation of ecosystem services. Ecol. Econ. 2006, 57, 209-228. [CrossRef]

13. De Groot, R.S.; Alkemade, R.; Braat, L.; Hein, L.; Willemen, L. Challenges in integrating the concept of ecosystem services and values in landscape planning, management and decision making. Ecol. Complex. 2010, 7, 260-272. [CrossRef]

14. Le Clec'h, S.; Oszwald, J.; Decaens, T.; Desjardins, T.; Dufour, S.; Grimaldi, M.; Jegou, N.; Lavelle, P. Mapping multiple ecosystem services indicators: Toward an objective-oriented approach. Ecol. Indic. 2016, 69, 508-521. [CrossRef]

15. Costanza, R. Ecosystem services: Multiple classification systems are needed. Biol. Conserv. 2008, 141, 350-352. [CrossRef]

16. Van Kamp, I.; Leidelmeijer, K.; Marsman, G. Urban environmental quality and human well-being. Towards a conceptual framework and demarcation of concepts; a literature study. Landsc. Urban Plan. 2003, 65, 5-18. [CrossRef]

17. Antognelli, S.; Vizzari, M. Landscape liveability spatial assessment integrating ecosystem and urban services with their perceived importance by stakeholders. Ecol. Indic. 2017, 72, 703-725. [CrossRef]

18. De Haan, F.J.; Ferguson, B.C.; Adamowicz, R.C.; Johnstone, P.; Brown, R.R.; Wong, T.H.F. The needs of society: A new understanding of transitions, sustainability and liveability. Technol. Forecast. Soc. Chang. 2014, 85, 121-132. [CrossRef]

19. Norouzian-Maleki, S.; Bell, S.; Hosseini, S.-B.; Faizi, M. Developing and testing a framework for the assessment of neighbourhood liveability in two contrasting countries: Iran and Estonia. Ecol. Indic. 2015, 48, 263-271. [CrossRef]

20. Shamsuddin, S.; Hassan, N.R.A.; Bilyamin, S.F.I. Walkable Environment in Increasing the Liveability of a City. Procedia Soc. Behav. Sci. 2012, 50, 167-178. [CrossRef]

21. Kubiszewski, I.; Costanza, R.; Anderson, S.; Sutton, P. The future value of ecosystem services: Global scenarios and national implications. Ecosyst. Serv. 2017, 26, 289-301. [CrossRef]

22. Burkhard, B.; Kroll, F.; Nedkov, S.; Müller, F. Mapping ecosystem service supply, demand and budgets. Ecol. Indic. 2012, 21, 17-29. [CrossRef] 
23. Fischer, A.; Eastwood, A. Coproduction of ecosystem services as human-nature interactions-An analytical framework. Land Use Policy 2016, 52, 41-50. [CrossRef]

24. Kroll, F.; Müller, F.; Haase, D.; Fohrer, N. Rural-urban gradient analysis of ecosystem services supply and demand dynamics. Land Use Policy 2012, 29, 521-535. [CrossRef]

25. Burkhard, B.; Kandziora, M.; Hou, Y.; Müller, F. Ecosystem Service Potentials, Flows and Demands-Concepts for Spatial Localisation, Indication and Quantification. Landsc. Online 2014, 32, 1-32. [CrossRef]

26. Salvati, L.; Carlucci, M. Urban Growth and Land-Use Structure in Two Mediterranean Regions: An Exploratory Spatial Data Analysis. SAGE Open 2014, 4, 1-13. [CrossRef]

27. Briassoulis, H. Policy-oriented integrated analysis of land-use change: An analysis of data needs. Environ. Manag. 2001, 27, 1-11. [CrossRef] [PubMed]

28. Smith, B.A. Measuring the value of urban amenities. J. Urban Econ. 1978, 5, 370-387. [CrossRef]

29. Bagstad, K.J.; Johnson, G.W.; Voigt, B.; Villa, F. Spatial dynamics of ecosystem service flows: A comprehensive approach to quantifying actual services. Ecosyst. Serv. 2013, 4, 117-125. [CrossRef]

30. Serna-Chavez, H.M.; Schulp, C.J.E.; Van Bodegom, P.M.; Bouten, W.; Verburg, P.H.; Davidson, M.D. A quantitative framework for assessing spatial flows of ecosystem services. Ecol. Indic. 2014, 39, 24-33. [CrossRef]

31. Bastian, O.; Grunewald, K.; Syrbe, R.U.; Walz, U.; Wende, W. Landscape services: The concept and its practical relevance. Landsc. Ecol. 2014, 29, 1463-1479. [CrossRef]

32. Egarter Vigl, L.; Depellegrin, D.; Pereira, P.; de Groot, R.; Tappeiner, U. Mapping the ecosystem service delivery chain: Capacity, flow, and demand pertaining to aesthetic experiences in mountain landscapes. Sci. Total Environ. 2017, 574, 422-436. [CrossRef] [PubMed]

33. Bagstad, K.J.; Villa, F.; Batker, D.; Harrison-Cox, J.; Voigt, B.; Johnson, G.W. From theoretical to actual ecosystem services: Mapping beneficiaries and spatial flows in ecosystem service assessments. Ecol. Soc. 2014, 19. [CrossRef]

34. Fisher, B.; Turner, R.K.; Morling, P. Defining and classifying ecosystem services for decision making. Ecol. Econ. 2009, 68, 643-653. [CrossRef]

35. Lin, T.; Xia, J.; Robinson, T.P.; Goulias, K.G.; Church, R.L.; Olaru, D.; Tapin, J.; Han, R. Spatial analysis of access to and accessibility surrounding train stations: A case study of accessibility for the elderly in Perth, Western Australia. J. Transp. Geogr. 2014, 39, 111-120. [CrossRef]

36. Saarikoski, H.; Jax, K.; Harrison, P.A.; Primmer, E.; Barton, D.N.; Mononen, L.; Vihervaara, P.; Furman, E. Exploring operational ecosystem service definitions: The case of boreal forests. Ecosyst. Serv. 2015, 14, 144-157. [CrossRef]

37. Fisher, B.; Turner, R.K. Ecosystem services: Classification for valuation. Biol. Conserv. 2008, 141, 1167-1169. [CrossRef]

38. Haines-young, R.; Potschin, M. Common International Classification of Ecosystem Services (CICES): Consultation on Version 4, August-December 2012; CICES: Nottingham, UK, 2013.

39. Wolff, S.; Schulp, C.J.E.; Verburg, P.H. Mapping ecosystem services demand: A review of current research and future perspectives. Ecol. Indic. 2015, 55, 159-171. [CrossRef]

40. Vizzari, M.; Sigura, M. Urban-rural gradient detection using multivariate spatial analysis and landscape metrics. J. Agric. Eng. 2013, 44. [CrossRef]

41. Neri, M.; Menconi, M.E.; Vizzari, M.; Mennella, V.G.G. A proposal of a new methodology for best location of environmentally sustainable roads infrastructures. Validation along the Fabriano-Muccia road. Inf. la Constr. 2010, 62. [CrossRef]

42. Vizzari, M.; Hilal, M.; Sigura, M.; Antognelli, S.; Joly, D. Urban-rural-natural gradient analysis with CORINE data: An application to the metropolitan France. Landsc. Urban Plan. 2018, 171. [CrossRef]

43. Yin, R.K. A (very) brief refresher on the case study method. Appl. Case Study Res. 2012, 3-20. [CrossRef]

44. Vizzari, M.; Sigura, M.; Antognelli, S. Ecosystem Services Demand, Supply and Budget along the Urban-rural-natural gradient. In Proceedings of the 43th Interational Symposium "Actual Tasks on Agricultural Engeneering", Opatjia, Croatia, 24-27 February 2015; pp. 473-484.

45. Haines-Young, R.; Potschin, M. Proposal for a Common Classification of Ecosystem Good and Services (CICES) for Integrated Environmental and Economic Accounting; CICES: Nottingham, UK, 2010.

46. Peterson, G.E.; Muzzini, E. Decentralizing basic infrastructure services. In East Asia Decentralizes Making Local Government Work; World Bank: Washington, DC, USA, 2005; Volume 292, p. 209. 
47. Egoh, B.; Reyers, B.; Rouget, M.; Richardson, D.M.; Le Maitre, D.C.; van Jaarsveld, A.S. Mapping ecosystem services for planning and management. Agric. Ecosyst. Environ. 2008, 127, 135-140. [CrossRef]

48. Thériault, M.; Des Rosiers, F. Modelling Perceived Accessibility to Urban Amenities Using Fuzzy Logic, Transportation GIS and Origin-Destination Surveys. In Proceedings of the AGILE 2004 7th Conference on Geographic Information Science, Heraklion, Greece, 29 April-1 May 2004; pp. 475-485.

49. Schulp, C.J.E.; Lautenbach, S.; Verburg, P.H. Quantifying and mapping ecosystem services: Demand and supply of pollination in the European Union. Ecol. Indic. 2014, 36, 131-141. [CrossRef]

50. Bianchi, F.J.J.A.; Booij, C.J.H.; Tscharntke, T. Sustainable pest regulation in agricultural landscapes: A review on landscape composition, biodiversity and natural pest control. Proc. Biol. Sci. 2006, 273, 1715-1727. [CrossRef] [PubMed]

51. Petz, K.; Schulp, C.J.E.; Van Der Zanden, E.H.; Veerkamp, C.; Schelhaas, M.; Nabuurs, G.; Hengeveld, G. Indicators and modelling of land use, land management and ecosystem services. In Methodological Documentation Nature Outlook; PBL Netherlands Environmental Assessment Agency: Den Haag, The Netherlands, 2016.

52. Fang, X.; Zhao, W.; Fu, B.; Ding, J. Landscape service capability, landscape service flow and landscape service demand: A new framework for landscape services and its use for landscape sustainability assessment. Prog. Phys. Geogr. 2015, 39, 817-836. [CrossRef]

53. Cash, D.W.; Adger, W.N.; Berkes, F.; Garden, P.; Lebel, L.; Olsson, P.; Pritchard, L.; Young, O. Cross-Scale Dynamics: Governance and Information in a Multilevel World. Ecol. Soc. 2006, 11, 8-19. [CrossRef]

54. Woodcock, B.A.; Edwards, M.; Redhead, J.; Meek, W.R.; Nuttall, P.; Falk, S.; Nowakowski, M.; Pywell, R.F. Crop flower visitation by honeybees, bumblebees and solitary bees: Behavioural differences and diversity responses to landscape. Agric. Ecosyst. Environ. 2013, 171, 1-8. [CrossRef]

55. Albert, C.; Galler, C.; Hermes, J.; Neuendorf, F.; von Haaren, C.; Lovett, A. Applying ecosystem services indicators in landscape planning and management: The ES-in-Planning framework. Ecol. Indic. 2015, 61, 100-113. [CrossRef]

56. Swetnam, R.D.; Fisher, B.; Mbilinyi, B.P.; Munishi, P.K.T.; Willcock, S.; Ricketts, T.; Mwakalila, S.; Balmford, A.; Burgess, N.D.; Marshall, A.R.; et al. Mapping socio-economic scenarios of land cover change: A GIS method to enable ecosystem service modelling. J. Environ. Manag. 2011, 92, 563-574. [CrossRef] [PubMed]

57. Lautenbach, S.; Maes, J.; Kattwinkel, M.; Seppelt, R.; Strauch, M.; Scholz, M.; Schulz-Zunkel, C.; Volk, M.; Weinert, J.; Dormann, C.F. Mapping water quality-related ecosystem services: Concepts and applications for nitrogen retention and pesticide risk reduction. Int. J. Biodivers. Sci. Ecosyst. Serv. Manag. 2012, 8, 1-2. [CrossRef]

58. Sumarga, E.; Hein, L. Mapping ecosystem services for land use planning, the case of Central Kalimantan. Environ. Manag. 2014, 54, 84-97. [CrossRef] [PubMed]

59. Mckenzie, E.; Posner, S.; Tillmann, P.; Bernhardt, J.R.; Howard, K.; Rosenthal, A. Understanding the use of ecosystem service knowledge in decision making: Lessons from international experiences of spatial planning. Environ. Plan. C Gov. Policy 2014, 32, 320-340. [CrossRef]

(c) 2018 by the authors. Licensee MDPI, Basel, Switzerland. This article is an open access article distributed under the terms and conditions of the Creative Commons Attribution (CC BY) license (http://creativecommons.org/licenses/by/4.0/). 